\title{
A radiographic method to estimate lung volume and its use in small mammals
}

\author{
MAURICIO CANALS ${ }^{1}$, RICARDO OLIVARES $^{2}$ and MARIO ROSENMANN ${ }^{1}(\dagger)$
}

1 Department of Ecological Sciences, Faculty of Science, University of Chile
2 Department of Animal Sciences, Faculty of Veterinary Medicine, University of Chile
$(\dagger)$ deceased

\begin{abstract}
In this paper we develop a method to estimate lung volume using chest x-rays of small mammals. We applied this method to assess the lung volume of several rodents. We showed that a good estimator of the lung volume is: $V_{L}^{*}=0.496 \cdot V_{R X} \approx 1 / 2 \cdot V_{R X}$, where $\mathrm{V}_{\mathrm{RX}}$ is a measurement obtained from the X-ray that represents the volume of a rectangular box containing the lungs and mediastinum organs. The proposed formula may be interpreted as the volume of an ellipsoid formed by both lungs joined at their bases. When that relationship was used to estimate lung volume, values similar to those expected from allometric relationship were found in four rodents. In two others, $M$. musculus and $R$. norvegicus, lung volume was similar to reported data, although values were lower than expected.
\end{abstract}

Key terms: Lung volume, x-ray, method, rodents

\section{INTRODUCTION}

Lung volume is one of the most relevant structural parameters related to the aerobic capacity of mammals. It is approximately linearly related to body mass (Stahl, 1967; Gehr et al., 1981), constituting about $5 \%$ of the body mass (Calder, 1996; SchmidtNielsen, 1984). The volume of the lungs is related to oxygen diffusing capacity $\left(\mathrm{D}_{\mathrm{LO} 2}\right)$ and oxygen consumption $\left(\dot{V}_{O 2}\right)$ (Maina $2000)$ by the relationship: $\dot{V}_{\mathrm{O} 2}=D_{\mathrm{LO} 2} \cdot \Delta P_{\mathrm{O} 2}$, where $\Delta \mathrm{P}_{\mathrm{O} 2}$ is the gradient of partial pressures between alveoli and capillaries. The oxygen diffusing capacity may be described as: $\mathrm{D}_{\mathrm{LO} 2}=\kappa \cdot \frac{d S A \cdot V_{L}}{\tau_{h}}$ where $\kappa$ is the

Krohg's diffusion coefficient, dSA is the alveolar surface density $\left(\mathrm{m}^{2} / \mathrm{l}\right), \mathrm{V}_{\mathrm{L}}$ is the lung volume, and $\tau_{\mathrm{h}}$ is the thickness of the blood-gas barrier (Maina 2000). Thus, larger lung volume may be a way to have both high oxygen diffusion capacity and high maximum oxygen flow.

To estimate oxygen diffusion capacity, the lung volume (tissue) is preferred to functional capacities. Although related, they are not the same. For example, Stahl found that in mammals lung volume and vital capacity (VC) were related to the body mass $\left(\mathrm{M}_{\mathrm{b}}\right)$ by $V_{L}=53.5 \cdot M^{1.06}{ }_{b}$ and $V_{L}=56.7 \cdot M_{b}{ }^{1.03}$ (Stahl 1967 cited in Schmidt-Nielsen 1984) respectively; in consequence the lung volume represented approximately $94.36 \%$ of the vital capacity with a negligible residual mass exponent RME $=0.03$. Given that vital capacity is approximately $75 \%$ of the total lung capacity (TLC), the lung volume represented about $70.1 \%$ of TLC. Weibel et al. (1981) reported that lung volume measured by water displacement underestimates the total lung capacity (TLC) by approximately 10-30\%. 
Methods for estimating lung volume are demanding because they usually require the removal of the lungs to directly measure the volume through water displacement methods (Scherle, 1970). Moreover, this procedure frequently produces a variable athelectasis or elastic retraction that has been estimated to be approximately $5 \%$ in the first few hours (Weibel et al., 1981). Other techniques, such as nitrogen washout, helium dilution technique, plethysmography, and radiographicplanimetric methods have been developed to estimate functional lung capacities (Kilburn et al., 1993). In this regard, the Barnhard-Loyd radiographic method has good correlations with the other methodologies in estimating total lung capacity in humans (Barnhard et al., 1960, Loyd et al., 1966, Kilburn et al., 1993, Pappas et al., 1998). It considers the thorax to be a stack of five elliptical sections that allow an estimation of the lung volume by integration from measures of transverse diameters and heights in anteroposterior and lateral chest $\mathrm{x}$-rays. Although the Barnhard-Loyd radiographic method appears to be as accurate as pletysmography, it does not seem to have gained wide use, probably because it is a lengthy process requiring as much as 30 minutes for the determination of total lung capacity (Rodgers and Tannen, 1983). The use of this method in small animals is limited by the size of the lungs, and the idea of correlate lung volume with chest $\mathrm{x}$ rays appears to be superior.

This paper aims to correlate the lung volume measured by water displacement with fixed measurable parameters in chest $\mathrm{x}$-rays of small rodents. We hope that these parameters will be useful in estimating lung volume. This method could be useful for studying the ontogeny of lung volume and making inter-specific comparisons.

\section{MATERIAL AND METHODS}

To estimate the relationship between lung volume measured by a water displacement method and the value estimated from thorax $\mathrm{x}$-rays, 12 individuals of three small mammal species were used: Mus musculus $(\mathrm{n}=6)$ (30.9 $\pm 4.16 \mathrm{~g}$, mean \pm standard deviation)), Rattus norvegicus $(\mathrm{n}=2)(297.0 \pm 79.97 \mathrm{~g})$ and Cricetus auratus $(\mathrm{n}=4)(41.7 \pm 5.26 \mathrm{~g})$.

Animals were sacrificed by means of $\mathrm{CO}_{2}$ exposure, and chest $\mathrm{x}$-rays were taken. All experiments comply with the current laws of Chile and the Ethical Committee of the Faculty of Sciences of the University of Chile, where the experiments were performed. All x-rays were obtained with a standardized technique of $300 \mathrm{~mA}, 0.05 \mathrm{~s}$ and $50 \mathrm{kV}$ and with $1 \mathrm{~m}$ of object-focus distance, a sufficient distance to make magnification negligible.

On the images of the lungs, a straight line (RL) was traced between the two costophrenic recesses, and the following magnitudes were measured: i) the width of $\mathrm{RL}(\mathrm{W})$ as a transversal measure; ii) the height between RL and the top of the left $\left(\mathrm{H}_{1}\right)$ and the right $\left(\mathrm{H}_{2}\right)$ lung; and iii) left $\left(\mathrm{w}_{1}\right)$ and right $\left(\mathrm{w}_{2}\right)$ lung width on the middle point of diaphragm domes. Both $\mathrm{w}_{1}$ and $\mathrm{w}_{2}$ were used as estimators of the anteroposterior diameters of lungs, assuming circular lung sections (Fig. 1).

These measurements were used to build a rectangular box with a volume of: $V_{R X}=$ $\mathrm{W} \cdot\left(\frac{H_{1}+H_{2}}{2}\right) \cdot\left(\frac{w_{1}+w_{2}}{2}\right)$ to contain the lungs and mediastinum organs. Given that $\mathrm{V}_{\mathrm{RX}}$ is a dimensional volumetric characteristic $\left(\mathrm{L}^{3}\right)$ that contains the actual lung volume $\left(\mathrm{V}_{\mathrm{L}}\right)$, we expected both variables be tightly correlated.

Next we performed a small tracheotomy and instilled the lungs with a $2.5 \%$ Glutaraldehide solution with a plastic catheter. The trachea was ligated to keep the intrapulmonary fixative volume and a small quantity of latex or auto-curable acrylic was introduced to fill the airway and avoid collapse. The next day the lungs were removed by thoracotomy, and their actual volumes $\left(\mathrm{V}_{\mathrm{L}}\right)$ were estimated by means of a water displacement method (Scherle, 1970).

Correlation between $\mathrm{V}_{\mathrm{L}}$ and $\mathrm{V}_{\mathrm{RX}}$ was tested with student $t$ test: $t_{n-2}=\frac{r \sqrt{n-2}}{\sqrt{1-r^{2}}}$. The ratio $\mathrm{R}_{\mathrm{VL}}=\mathrm{V}_{\mathrm{L}} / \mathrm{V}_{\mathrm{RX}}(\bar{x} \pm 1 S d)$ 


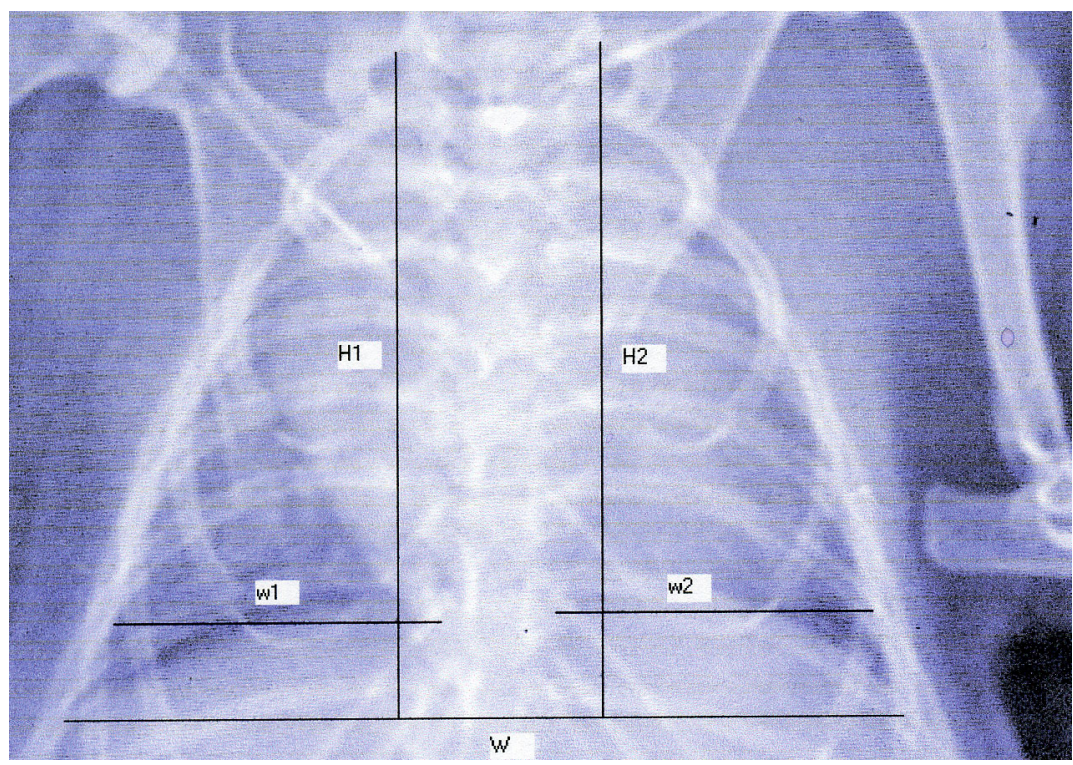

Figure 1. Thorax x-ray of one individual of Rattus norvegicus, showing the reference lines for the computation of $\mathrm{V}_{\mathrm{RX}}$.

was calculated as an estimator of the proportion of $\mathrm{V}_{\mathrm{RX}}$ that is filled by the lungs. Thereafter $V_{L}^{*}=R_{V L} \cdot V_{R X}$ would be a good estimator of lung volume $\left(\mathrm{V}_{\mathrm{L}}\right)$. The ratio between the true volume and the estimated volume, $\mathrm{R}=\mathrm{V}_{\mathrm{L}} / \mathrm{V}_{\mathrm{L}}{ }^{*}$, was computed for all individuals in this group, testing the hypotheses Ho: $\mathrm{R}=1$ vs $\mathrm{H}_{1}: \mathrm{R} \neq 1$ 1 with $t_{n-1}=\frac{\bar{R}-1}{\mathrm{~S}_{e R}}$.

A second group of 16 individuals of Mus muculus $(\mathrm{n}=2)$; Meriones unguiculatus ( $\mathrm{n}$ = 2); Abrothrix andinus $(\mathrm{n}=4)$; Abrothrix olivaceus $(\mathrm{n}=5)$; Phyllotis darwini $(\mathrm{n}=2)$; and Octodon degus $(\mathrm{n}=1)$ was analyzed, and the $\mathrm{V}_{\mathrm{L}}{ }^{*}$ was estimated from chest $\mathrm{x}$ rays. Lung volume estimations for this species were compared with the expected values from the allometric relationship $V_{L}=$ $0.046 \cdot M_{\mathrm{b}}{ }^{1.06}$, where $\mathrm{M}_{\mathrm{b}}$ is in kilograms and $\mathrm{V}_{\mathrm{L}}$ in liters (Gehr et al., 1981).

\section{RESULTS}

The lung-filling method produced good results (Fig. 2), yielding, by water displacement, lung volume values similar to those observed by other authors for rats and mice: Mus musculus $0.69 \pm 0.08 \mathrm{ml}$; Rattus norvegicus $5.76 \pm 0.69 \mathrm{ml}$ and Cricetus auratus $1.56 \pm 0.34 \mathrm{ml}$ (Table I).

A good correlation between $\mathrm{V}_{\mathrm{RX}}$ and $\mathrm{V}_{\mathrm{L}}$ was found $\left(\mathrm{r}=0.992, \mathrm{t}_{10}=24.85, \mathrm{p}<0.01\right)$. The ratio $R_{V L}$ was $0.496 \pm 0.138$, and we could then estimate the lung volume from thorax X-rays by means of: $V^{*}{ }_{L}=0.496 \cdot V_{R X}$.

The ratio between the actual lung volume and the radiographically-estimated lung volume, $\mathrm{R}=\mathrm{V}_{\mathrm{L}} / \mathrm{V}_{\mathrm{L}}{ }^{*}=0.997 \pm 0.279$ was not significantly different from the unit ( $p>0.05$ ). A good correlation between $V_{R X}$ and $\mathrm{V}_{\mathrm{L}}$ was found $\left(\mathrm{r}=0.992, \mathrm{t}_{10}=24.85\right.$, $\mathrm{p}<<0.01)$.

The estimations of the lung volume $\left(\mathrm{V}_{\mathrm{L}}{ }^{*}\right)$ from $\mathrm{x}$-rays and the expected values from Gehr's relationships for all individuals (the original 12 plus the additional 16) are summarized in Table II.

\section{DISCUSSION}

The method of filling the lungs yielded good results and avoided a significant retraction of the parenchyma when the lungs were removed. Previous reports suggest that the lung may lose approximately $5 \%$ of its volume in the first hours after removal due to elastic recoil, but then remains constant for weeks. Our 

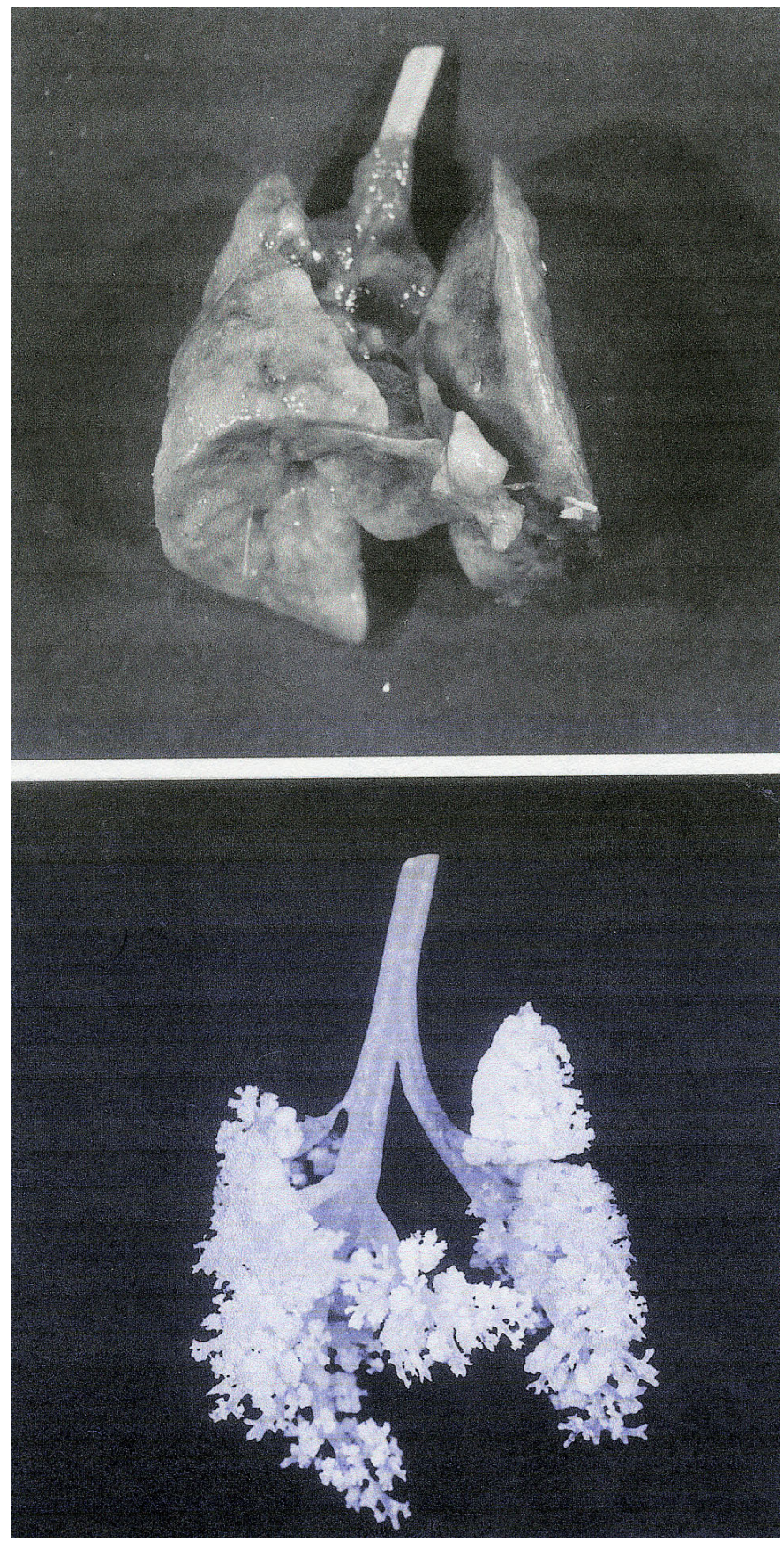

Figure 2. Lungs of an individual of Rattus norvegicus with the airway filled with auto-curable acrylic (top). The same sample after washing with $25 \% \mathrm{KOH}$ solution, showing the good filling of the airway. 


\section{TABLE I}

Relationships between the water displacement lung volume $\left(\mathrm{V}_{\mathrm{L}}\right)$, the $\mathrm{X}$-ray box volume $\left(\mathrm{V}_{\mathrm{RX}}\right)$, estimated lung volume $\left(\mathrm{V}_{\mathrm{L}}{ }^{*}\right)$ from chest $\mathrm{x}$-rays and the expected lung volume $\left(\mathrm{EV}_{\mathrm{L}}\right)$ from Gehr's allometric relationship for twelve individuals of three small mammal species. Mb is body mass and $R_{V L}=V_{L} / V_{R X}$

\begin{tabular}{lcccccc}
\hline \multicolumn{1}{c}{ Species } & $\mathrm{Mb}(\mathrm{g})$ & $\mathrm{V}_{\mathrm{L}}(\mathrm{ml})$ & $\mathrm{V}_{\mathrm{RX}}(\mathrm{ml})$ & $\mathrm{R}_{\mathrm{VL}}$ & $\mathrm{V}_{\mathrm{L}}{ }^{*}(\mathrm{ml})$ & $\mathrm{EV}_{\mathrm{L}}(\mathrm{ml})$ \\
\hline M.musculus & 37.8 & 0.80 & 1.33 & 0.601 & 0.66 & 1.42 \\
M.musculus & 30.7 & 0.62 & 1.79 & 0.349 & 0.89 & 1.15 \\
M.musculus & 31.9 & 0.77 & 1.71 & 0.447 & 0.85 & 1.19 \\
M.musculus & 31.9 & 0.60 & 1.32 & 0.369 & 0.80 & 1.19 \\
M.musculus & 26.9 & 0.68 & 1.69 & 0.486 & 0.69 & 0.99 \\
M.musculus & 26.3 & 0.68 & 1.66 & 0.407 & 0.82 & 1.09 \\
$\bar{x} \pm 1 S d$ & & $0.69 \pm 0.08$ & $1.58 \pm 0.20$ & $0.44 \pm 0.09$ & $0.79 \pm 0.09$ & $1.17 \pm 0.14$ \\
M.auratus & 43.3 & 1.61 & 2.46 & 0.629 & 1.27 & 1.65 \\
M.auratus & 39.5 & 1.44 & 2.05 & 0.702 & 1.01 & 1.50 \\
M.auratus & 35.9 & 1.19 & 2.59 & 0.459 & 1.29 & 1.35 \\
M.auratus & 48.2 & 1.99 & 2.67 & 0.745 & 1.32 & 1.85 \\
$\quad \bar{x} \pm 1 S d$ & & $1.56 \pm 0.37$ & $2.44 \pm 0.28$ & $0.63 \pm 0.13$ & $1.22 \pm 0.14$ & $1.59 \pm 0.21$ \\
R.norvegicus & 353.5 & 6.25 & 17.12 & 0.365 & 8.49 & 15.27 \\
R.norvegicus & 240.4 & 5.27 & 13.43 & 0.392 & 6.66 & 10.15 \\
$\bar{x} \pm 1 S d$ & & $5.76 \pm 0.69$ & $15.28 \pm 2.61$ & $0.38 \pm 0.02$ & $7.58 \pm 1.29$ & $12.71 \pm 3.62$
\end{tabular}

TABLE II

Average lung volume $\left(\mathrm{V}_{\mathrm{L}}\right)$, X-ray box volume $\left(\mathrm{V}_{\mathrm{RX}}\right)$, estimated lung volume $\left(\mathrm{V}_{\mathrm{L}}{ }^{*}\right)$ from $\mathrm{x}$ rays and expected lung volume $\left(\mathrm{EV}_{\mathrm{L}}\right)$ from Gehr's allometric relationship for the species Abrothrix andinus, Abrothrix olivaceus, Meriones unguiculatus, Microcricetus auratus, Mus musculus, Octodon degus, Phyllotis darwini and Rattus norvegicus

\begin{tabular}{lccccc}
\hline \multicolumn{1}{c}{ Species } & $\begin{array}{c}\text { Body mass } \\
(x \pm 1 S d)\end{array}$ & $\begin{array}{c}\mathrm{V}_{\mathrm{L}}{ }^{*} \\
(\mathrm{x} \pm 1 S d) \\
(\mathrm{ml})\end{array}$ & $\begin{array}{c}\mathrm{V}_{\mathrm{L}} \\
(\bar{x} \pm 1 S d) \\
(\mathrm{ml})\end{array}$ & $\begin{array}{c}\mathrm{EV}_{\mathrm{L}} \\
(\mathrm{ml})\end{array}$ & $\begin{array}{c}\mathrm{V}_{\mathrm{RX}} \\
(\bar{x} \pm 1 S d) \\
(\mathrm{ml})\end{array}$ \\
\hline Abrothrix andinus (4) & $25.48 \pm 3.23$ & $1.08 \pm 0.12$ & - & 0.94 & $2.18 \pm 0.23$ \\
Abrothrix olivaceus (5) & $26.30 \pm 6.75$ & $0.94 \pm 0.28$ & - & 0.97 & $1.89 \pm 0.57$ \\
Meriones unguiculatus (2) & $65.85 \pm 2.62$ & $1.82 \pm 0.07$ & - & 2.57 & $3.66 \pm 0.14$ \\
Cricetus auratus (4) & $41.73 \pm 5.27$ & $1.22 \pm 0.14$ & $1.56 \pm 0.34$ & 1.59 & $2.47 \pm 0.28$ \\
Mus musculus (8) & $32.73 \pm 3.93$ & $0.77 \pm 0.08$ & $0.69 \pm 0.08$ & 1.22 & $1.56 \pm 0.16$ \\
Octodon degus (1) & $136.1 \pm 0.00$ & $2.53 \pm 0.00$ & - & 5.55 & $5.09 \pm 0.00$ \\
Phyllotis darwini (2) & $54.85 \pm 2.62$ & $1.52 \pm 0.31$ & - & 2.43 & $3.06 \pm 0.64$ \\
Rattus norvegicus (2) & $297.0 \pm 79.97$ & $7.58 \pm 1.29$ & $5.76 \pm 0.69$ & 12.7 & $14.64 \pm 2.14$ \\
\hline
\end{tabular}

lung volume measurements were made the day after removal, so we did not expect recoils larger than this value. Our estimations of lung volume were within the range of what has been previously reported for these species. For example, our values of lung volume for $R$. norvegicus and $M$. musculus, $5.76 \pm 0.69 \mathrm{ml}$ and $0.69 \pm 0.08$ $\mathrm{ml}$ respectively, are within the range of 6.3 $\pm 0.2 \mathrm{ml}$ and $0.74 \pm 0.075 \mathrm{ml}$ reported for rats and mice (Weibel, 1973). However, when body mass was introduced into the allometric relationship between body mass and lung volume: $V_{L}=0.046 \cdot M^{1.06}{ }_{b}$, where $\mathrm{M}_{\mathrm{b}}$ is in kilograms and $\mathrm{V}_{\mathrm{L}}$ in liters (Gehr et al., 1981), the expected values for the lung's volume were larger than those obtained in our sample of M. musculus and $R$. norvegicus. However, it is known that mice and rats have smaller lungs than those expected as a result of Gehr's relationship. For example, Standaert et al (1985) studied 6 rats $(286.67 \pm 184.1 \mathrm{~g})$ and obtained an average lung volume of $9.59 \pm 4.58 \mathrm{ml}$, 
while the expected volume from Gehr's relationship is $12.35 \pm 8.4 \mathrm{ml}$.

The $\mathrm{x}$-ray box volume, $\mathrm{V}_{\mathrm{RX}}$, was easy to measure and showed that the variability in results was similar to that found in measured lung volume $\left(\mathrm{V}_{\mathrm{L}}\right)$. The coefficients of variation were $\mathrm{CV}=1.27$ and $\mathrm{CV}=1.33$ respectively $(\mathrm{p}>0.05)$. Lung volume filled approximately one half of $\mathrm{V}_{\mathrm{RX}}$ volume.

Several geometric figures have been proposed as models of lung and chest transversal sections, such as circles, ellipses and rectangles bounded by two semicircles (Chihara et al., 1996). We did not use any preconceived model in our method. We preferred to build a rectangular box that contained the lungs and ask how much of that box volume was filled by the lungs. Working with infants and using a similar methodology, Thome et al. (1998) found poor correlations between lung volume and both the sum of the right and left radiographic lung areas $(r=0.44)$ and the product of the distances between both costophrenic angles ( $\mathrm{W}$ in our terminology) and the lung height $(\mathrm{H})(\mathrm{r}=0.37)$, although we found good correlation between $V_{R X}$ and $\mathrm{V}_{\mathrm{L}}(\mathrm{r}=0.992)$. This fact may be explained by the fact that Thome et al. tried to correlate magnitudes that are dimensionally different: sectional lung area $\left(\mathrm{L}^{2}\right)$ and lung volume $\left(\mathrm{L}^{3}\right)$. We corrected this problem, considering the width of lungs at diaphragm domes to be an estimation of anteroposterior diameter. This is a good assumption if lung sections are nearly circular as in several small mammals; however this may be a problem in very asymmetric lungs.

When we averaging over all individuals, we found that $0.496 \pm 0.138$ of $\mathrm{V}_{\mathrm{RX}}$ is filled by the lungs, but when averaging over the species, we found $0.485 \pm 0.133$. These values are not different and very close to 0.5 . This result is very interesting because although our method is absolutely different than Barnhard-Loyd planimetric approximation, in some sense it agrees with the proposed elliptic models. In an ellipsoid the volume is $V=\frac{4}{3} \pi \cdot\left(\frac{a \cdot b \cdot c}{8}\right)=0.523 \cdot a \cdot b \cdot c \approx 1 / 2 \cdot a \cdot b \cdot c$ where $\mathrm{a}, \mathrm{b}$, and $\mathrm{c}$ are the three transversal diameters of the ellipsoid, a common formula used in medical practice to estimate volumes such as cyst, prostate, and heart volumes (Keats and Sistrom, 2002). If we rearrange the relationship for $V_{R X}$ as:

$V_{R X}=W / 2 \cdot\left(H_{1}+H_{2}\right) \cdot\left(\frac{w_{1}+w_{2}}{2}\right)$, we observe

that $W / 2$ represents half of the width of the $\mathrm{x}$-ray rectangular box (the width of the lung basis) (a), that $\left(\mathrm{H}_{1}+\mathrm{H}_{2}\right)$ is the sum of the height of each lung, which we can interpret as the height of both lungs joined at their bases (b), and $\left(\mathrm{w}_{1}+\mathrm{w}_{2}\right) / 2$ estimates the anteroposterior diameter of the lungs (c). Therefore, the proposed formula $V^{*}=0.496 \cdot V_{R X} \approx 1 / 2 \cdot V_{R X}$ may be interpreted to be the volume of an ellipsoid formed by both lungs joined at their bases.

When the relationship $V_{L}^{*}=0.496 \cdot V_{R X}$ was used to estimate lung volume, we obtained values similar to those expected for A. andinus, A. olivaceus, $M$. unguiculatus and $C$. auratus. However, lung volume estimations were lower than the predicted in $M$. musculus, $R$. norvegicus, $O$. degus and $P$. darwini, but the lung volume values for mice and rats agree with previously-reported data. As mentioned above, several rodents, including rats and mice, have lung volumes that are lower than the expected values from allometric relationships. All of the species we studied were rodents with lung volumes ranging between $48.5 \%$ and $114.9 \%$ of the expected values expected from allometry $(73.8 \pm 26.3 \%)$. Gehr et al (1981) considered 4 rodents within the same range of body mass as those in our study; of those 4 , three had lung volumes that were lower than expected: Mus musculus (90.6\%), Rattus rattus (86.8\%) and Cavia porcellus $(69.5 \%)$ (Gehr et al., 1981).

In summary, the estimator $V_{L}^{*}=0.496$. $V_{R X} \approx 1 / 2 \cdot V_{R X}$ advanced in this study may be a rapid broad estimator of lung volume in small mammals, useful for inter-specific comparisons or for following ontogenetic changes in lung volume. The validity of the estimator in other mammals will be subject of future studies. 


\section{ACKNOWLEDGEMENTS}

This work was supported by the FONDECYT 1040649 grant and the DI ENL 03/04 grant from the Investigation Department of University of Chile to MCL. We thank Sebastian Castro and Felipe Oyarzún for technical assistance and José Iriarte-Díaz for idiomatic corrections. This paper is dedicated to the memory of our friend, colleague, 'maestro,' and mentor, Dr. Mario Rosenmann, PhD.

\section{REFERENCES}

BARNHARD HJ, PIERCE JA, JOICE JW, BATES JH (1960) Roetgenographic determination of total lung capacity. A new method evaluated in health, emphysema and congestive heart failure. Am J Med 28: 51-60

CALDER WA (1996) Size, function, and life history. Mineola, NY: Dover Publications, Inc.

CHIHARA K, KENYON CM, MACKLEM PT (1996) Human rib cage distortability. J Appl Physiol 81: 437447

GEHR P, MWANGI DK, AMMANN A, MALOIY GMO, TAYLOR CR, WEIBEL ER (1981) Design of the mammalian respiratory system. V. Scaling morphometric pulmonary diffusing capacity to body mass: wild and domestic mammals. Respir Physiol 44: 61-86

KEATS TE, SISTROM C (2002) Atlas de medidas radiológicas., $7^{\text {th }}$ ed. Madrid: Elsevier Science

KILBURN KH, MILLER A, WARSHAW RH (1993) Measuring lung volumes in advanced asbestosis: comparability of pletysmographic and radiographic versus helium rebreathing and single breath methods. Respir Med 87: 115-120

LOYD HM, STRING ST, DUBOIS AB (1966) Radiographic and plethysmographic determination of total lung capacity. Radiol 86: 7-14

MAINA JN (2000) Comparative respiratory morphology: Themes and principles in the design and construction of the gas exchangers. Anat Rec 261: 25-44

PAPPAS GP, BRODKIN CA, SHEPPARD L, BALMES J, HORIKE BS, BARNHART S (1998) The validity of radiographic estimation of total lung capacity in patients with respiratory disease. Chest 114: 513-520

RODGERS RP, TANNEN R (1983) Rapid and accurate determination of total lung capacity (TLC): routine chest radiograms using a programmable hand-held calculator. Comput Biol Med 13: 125-140

SCHERLE W (1970) A simple method for volumetry of organs in quantitative stereology. Mikroskopie 26: 57-60

SCHMIDT-NIELSEN K (1984) Scaling. Why is animal size so important? Cambridge: Cambridge University Press

STAHL WR (1967) Scaling of respiratory variables in mammals. J Appl Physiol 22: 453-460

STANDAERT TA, LA FRAMBOISE WA, TUCK RE, WOODRUM DE (1985) Serial determination of lung volume in small mammals by nitrogen washout. J Appl Physiol 59: 205-210

THOME U, TOPFER A, SCHALLER P, POHLANDT F (1998) Comparison of lung volume measurements by antero-posterior chest $\mathrm{x}$-ray and the $\mathrm{SF}_{6}$ washout technique in mechanically ventilated infants. Pediatric Pulmonol 26: 265-272

WEIBEL ER (1973) Morphological basis of alveolarcapillary gas exchange. Physiol Rev 53: 419-495

WEIBEL ER, GEHR P, CRUZ-ORI L, MULLER A.E, MWANGI DK, HAUSSENER V (1981) Design of the mammalian respiration system. IV. Morphometric estimation of pulmonary diffusing capacity: critical evaluation of a new sampling method. Respir Physiol 44: 39-59 